\title{
GABAb Receptor Mediates Opposing Adaptations of GABA Release From Two Types of Prefrontal Interneurons After Observational Fear
}

\author{
Lei Liu', Wataru Ito' and Alexei Morozov*,1,2,3 \\ 'Virginia Tech Carilion Research Institute, Roanoke, VA, USA; ${ }^{2}$ School of Biomedical Engineering and Sciences, Virginia Tech, Blacksburg, VA, USA; \\ ${ }^{3}$ Department of Psychiatry and Behavioral Medicine, Virginia Tech Carilion School of Medicine, Roanoke, VA, USA
}

\begin{abstract}
The observational fear (OF) paradigm in rodents, in which the subject is exposed to a distressed conspecific, elicits contextual fear learning and enhances future passive avoidance learning, which may model certain behavioral traits resulting from traumatic experiences in humans. As these behaviors affected by the OF require dorso-medial prefrontal cortex (dmPFC), we searched for synaptic adaptations in dmPFC resulting from $\mathrm{OF}$ in mice by recording synaptic responses in dmPFC layer $\mathrm{V}$ pyramidal neurons elicited by repeated $5 \mathrm{~Hz}$ electrical stimulation of dmPFC layer I or by optogenetic stimulation of specific interneurons ex vivo I day after OF. OF increased depression of inhibitory postsynaptic currents (IPSCs) along IPSC trains evoked by the $5 \mathrm{~Hz}$ electrical stimulation, but, surprisingly, decreased depression of dendritic IPSCs isolated after blocking GABAa receptor on the soma. Subsequent optogenetic analyses revealed increased depression of IPSCs originating from perisomatically projecting parvalbumin interneurons (PV-IPSCs), but decreased depression of IPSCs from dendritically projecting somatostatin cells (SOM-IPSCs). These changes were no longer detectable in the presence of a GABAb receptor antagonist CGP52432. Meanwhile, OF decreased the sensitivity of SOM-IPSCs, but not PV-IPSCs to a GABAb receptor agonist baclofen. Thus, OF causes opposing changes in GABAb receptor mediated suppression of GABA release from PV-positive and SOM-positive interneurons. Such adaptations may alter dmPFC connectivity with brain areas that target its deep vs superficial layers and thereby contribute to the behavioral consequences of the aversive experiences.

Neuropsychopharmacology (2017) 42, 1272-1283; doi: I0.1038/npp.2016.273; published online 4 January 2017
\end{abstract}

\section{INTRODUCTION}

Traumatic experiences, even those without physical pain, are a risk factor for mental disorders (Cougle et al, 2009; Resnick et al, 1995), but how they alter relevant neuronal circuits remains unknown. The observational fear $(\mathrm{OF})$ paradigm in rodent models certain components of socially induced trauma without physical pain or physical discomfort. The subject observer animal is exposed once to a conspecific demonstrator receiving electrical footshocks and emitting distress signals via multiple modalities. The distress signals act as an unconditional stimulus and lead to memorization of the associated cues and context (Chen et al, 2009; Jeon et al, 2010; Yusufishaq and Rosenkranz, 2013). We have recently shown that $\mathrm{OF}$ also enhances future learning in the passive avoidance (PA) task and causes the formation of silent synapses in the input from the dorso-medial prefrontal cortex (dmPFC) to the basolateral amygdala (Ito et al, 2015).

*Correspondence: Dr A Morozov, Virginia Tech Carilion Research Institute, Virginia Tech, 2 Riverside Circle, Roanoke, VA 24016, USA, Tel: 540-526-2021, Fax: 540-985-3373, E-mail: alexeim@vtc.vt.edu. Received 26 February 2016; revised 29 November 2016; accepted 2 December 2016; accepted article preview online 7 December 2016
As dmPFC is involved in Pavlovian conditioning (Malin et al, 2007; Malin and McGaugh, 2006) and undergoes synaptic remodeling during contextual fear learning (Bero et al, 2014), we hypothesized that OF also elicits plastic changes within dmPFC, which could potentially underlie the fear learning during $\mathrm{OF}$, or the stronger PA learning in the future. We searched for changes at synapses that target pyramidal cells (PCs) in dmPFC layer V. These cells belong to dmPFC major output neurons. They innervate multiple targets including the cortex, amygdala, striatum, thalamus, brainstem nuclei and spinal cord (Gabbott et al, 2005; Hirai et al, 2012; Shepherd, 2013). As their apical dendrites extend towards the superficial layer of $\mathrm{dmPFC}$, the layer V PC are positioned to integrate information from all cortical layers by receiving inputs from local neurons and remote projections from all over the brain (Ramaswamy and Markram, 2015). Our analysis suggests that OF redistributes flow of that information by reorganizing inhibitory control of inputs to the layer $\mathrm{V}$ neurons by two types of interneurons that are distinguished by expression of parvalbumin (PV) and somatostatin (SOM). 


\section{MATERIALS AND METHODS}

\section{Animals}

C57BL/6N males were crossed with 129SvEv females to obtain wild-type mice or with homozygous 129SvEv interneuron-specific Cre-driver females for interneuronspecific expression of ChR2. Male pups were housed two littermates per cage (Allentown, NJ) since weaning as detailed in Ito et al (2015). All experiments were approved by Virginia Tech IACUC and followed the NIH Guide for the Care and Use of Laboratory Animals.

\section{Viral Injection Surgery}

ChR2-AAV pseudo-type 1 virus containing Cre-activated ChR2 gene was prepared by the University of North Carolina Gene Therapy Vector Core (Chapel Hill, NC) using a plasmid pAAV-EF1a-double floxed- $h C h R 2$ (H134R)-EYFP (Addgene 20298). Heterozygous male Pvalb ${ }^{\text {tm1(cre)Arbr }}$ (Hippenmeyer et al, 2005) or Sst ${ }^{\text {tm2.1(cre)Zjh (Taniguchi }}$ et al, 2011) transgenic mice were injected bilaterally with $0.5 \mu \mathrm{l}$ of the viral solution ( $10^{8}$ viral particles) per hemisphere in $\mathrm{dmPFC}$ at $1.3 \mathrm{~mm}$ anterior, $0.4 \mathrm{~mm}$ lateral from the bregma, and $1.3 \mathrm{~mm}$ ventral from brain surface, as described (Ito et al, 2015). Previous studies have demonstrated specific expression of ChR2 in SOM-INs and PV interneurons (PVINs) of dmPFC using these lines and AAV vector (Kim et al, 2016; Sohal et al, 2009).

\section{Behavior}

OF procedure (Jeon et al, 2010) was performed at age of p60-75 during light phase of the day cycle in a fear conditioning chamber (Med Associates, St Albans, VT), divided into two unequal compartments by a transparent Plexiglas wall with $7 \mathrm{~mm}$ diameter holes, spaced at $2 \mathrm{~cm}$ interval, to allow auditory and olfactory cues and whisker-towhisker interaction. In the larger $26 \times 20 \times 26 \mathrm{~cm}$ (depth, width, height) compartment, a stainless-steel rod floor was covered with a white plastic sheet. In the smaller $26 \times 9 \times 26 \mathrm{~cm}$ compartment, the rod floor was exposed. Cagemates observer and demonstrator were placed in the larger and the smaller compartments, respectively. After $5 \mathrm{~min}$ acclimation, 24 footshocks ( $1 \mathrm{~mA}, 2 \mathrm{~s}$, every $10 \mathrm{~s})$ were delivered to the demonstrator. In the control procedure, demonstrators did not receive footshocks. The observers (OF or controls) were returned to the home cage and housed alone until preparation of brain slices for physiology on the next day.

\section{Electrophysiology}

Next day after OF training, under deep isoflurane anesthesia, animals were decapitated. Brains were immersed in an icecooled cutting solution containing (in $\mathrm{mM}$ ) 110 Choline $\mathrm{Cl}$, $2.5 \mathrm{KCl}, 1.2 \mathrm{NaH}_{2} \mathrm{PO}_{4}, 2.5 \mathrm{NaHCO}_{3}, 20$ glucose, $0.5 \mathrm{CaCl}_{2}$, and $5 \mathrm{MgSO}_{4}$, and bubbled with a $95 \% \mathrm{O}_{2} / 5 \% \mathrm{CO}_{2}$. Coronal dmPFC slices, $300 \mu \mathrm{m}$ thick, were cut using DSK Microslicer (Ted Pella, Redding, CA) and incubated in solution containing (in $\mathrm{mM}$ ) $120 \mathrm{NaCl}, 3.3 \mathrm{KCl}, 1.0 \mathrm{NaH}_{2} \mathrm{PO}_{4}, 25 \mathrm{NaHCO}_{3}$, 10 glucose, $0.5 \mathrm{CaCl}_{2}$, and $5 \mathrm{MgSO}_{4}$, bubbled with $95 \% \mathrm{O}_{2} /$ $5 \% \mathrm{CO}_{2}$ gas mixture at room temperature for at least $1 \mathrm{~h}$ before recording. Recording chamber was superfused at $2 \mathrm{ml} / \mathrm{min}$ with ACSF equilibrated with $95 \% \mathrm{O}_{2} / 5 \% \mathrm{CO}_{2}$ and containing $120 \mathrm{NaCl}, 3.3 \mathrm{KCl}, 1.0 \mathrm{NaH}_{2} \mathrm{PO}_{4}, 25 \mathrm{NaHCO}_{3}, 10$ glucose, $2 \mathrm{CaCl}_{2}$, and $1 \mathrm{MgCl}_{2}$. Whole-cell recordings were obtained at $30 \pm 1{ }^{\circ} \mathrm{C}$ with Multiclamp 700B amplifier and Digidata 1440 A (Molecular Device, Sunnyvale, CA). Putative layer $\mathrm{V}$ principle neurons in $\mathrm{dmPFC}$ were identified by their pyramidal morphology under the Dodt gradient contrast optics (custom made) at $850 \mathrm{~nm}$ LED illumination (Thorlabs, Newton, NJ) and were recorded using 4-6 $M \Omega$ pipettes filled with $\mathrm{K}+$-based internal solution (in $\mathrm{mM}$ ): $130 \mathrm{~K}$ gluconate, $1 \mathrm{MgCl}_{2}, 10 \mathrm{HEPES}, 0.2$ EGTA, 2 ATP-Mg, 0.1 GTP-Na pH 7.3, or Cs+-based internal solution (in mM): 120 Cs-methanesulfonate, $5 \mathrm{NaCl}, 1 \mathrm{MgCl}_{2}, 10$ HEPES, 0.2 EGTA, 2 ATP-Mg, 0.1 GTP-Na, and 5 QX314 pH 7.3, osmolarity 285 Osm. Series resistance (Rs) was 10-20 M $\Omega$ and monitored throughout experiments. Data were not included in the analysis if Rs changed $>20 \%$. All membrane potentials were corrected for the junction potential of $12 \mathrm{mV}$. For electrical stimulation of layer I, $0.1 \mathrm{~ms}$ pulses of current, 30-80 $\mu \mathrm{A}$ range, were delivered via a $6 \mathrm{M} \Omega$ pipette filled with ASCF. The current was adjusted to obtain postsynaptic responses as described in results. Light pulses $(470 \mathrm{~nm}, 1 \mathrm{~ms})$ were generated using an LED lamp (Thorlabs) and a custom LED driver based on MOSFET, and were delivered through a $\times 40$ objective lens (Olympus, Center Valley, PA) at 0.3$2.5 \mathrm{~mW}$, calibrated by a photodiode power sensor (Thorlabs) at the tip of the lens. In some experiments, to block somatic components of evoked inhibitory postsynaptic currents (IPSCs), picrotoxin $(1 \mathrm{mM})$ was puffed on the soma of recorded neurons via a $1-2 \mathrm{M} \Omega$ pipette, positioned at $\sim 50 \mu \mathrm{m}$ from the target, by three $300 \mathrm{~ms}$ puffs driven by 1 psi air pressure (PDES-02DX, NPI Electronic GmbH, Tamm, Germany). The spread of picrotoxin towards apical dendrites was minimized by directing the puffing and the flow of ACSF from superficial to deep layers of dmPFC. In most experiments, data from each cell were obtained from 19 to 20 stimuli sweeps separated by $20 \mathrm{~s}$ intervals. Baclofen and CGP52432 were from Tocris (Bristol, UK) and remaining chemicals were from Sigma-Aldrich (St Louis, MO).

\section{Data Analysis}

Statistical analyses were performed using GraphPad Prism (GraphPad Software, La Jolla, CA) and StatView (SAS Institute, Cary, NC). Charge transfer (voltage clamp) or EPSP time integral (current clamp) were measured as the area under the trace during a $45 \mathrm{~ms}$ time window starting $1.5 \mathrm{~ms}$ after the stimulus artifact or stimulus onset for electrical and blue light stimulation, respectively. Differences were tested using the two-tailed unpaired, paired and one sample $t$-test, repeated measure, one- or two-way ANOVA, and Bonferroni multiple comparisons as appropriate, and deemed significant with $p<0.05$.

\section{RESULTS}

OF Training Increases Excitability of L5 PCs and Causes EPSP Facilitation During Repetitive Stimuli

To study effects of OF on glutamatergic transmission, dmPFC layer I was stimulated with $5 \mathrm{~Hz}$ trains of five 
a

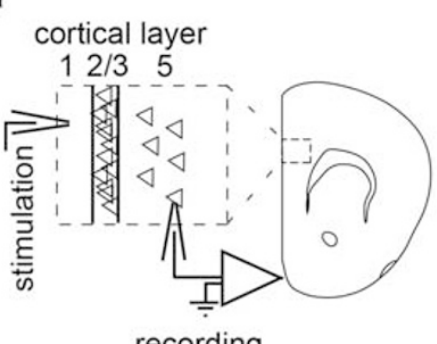

recording b

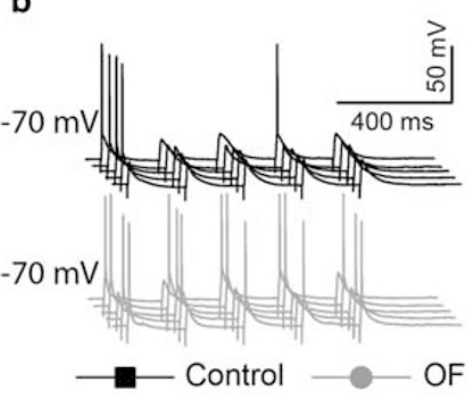

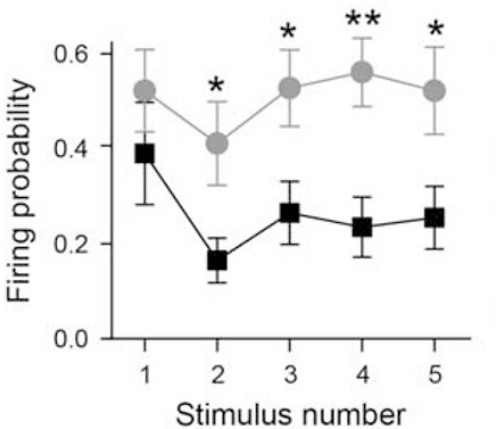

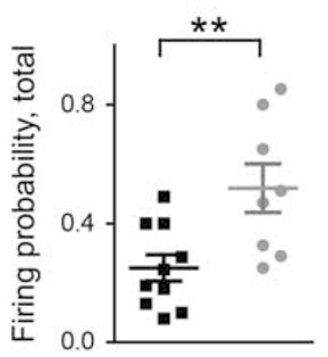

C

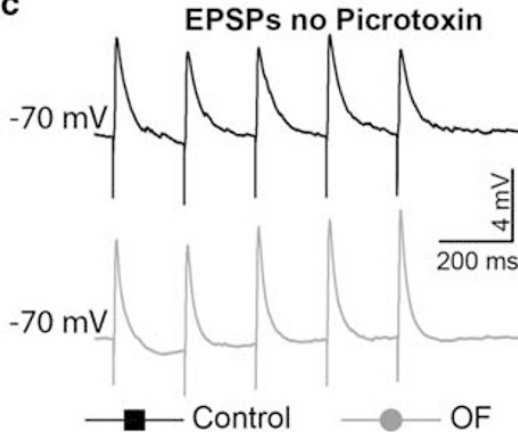

d

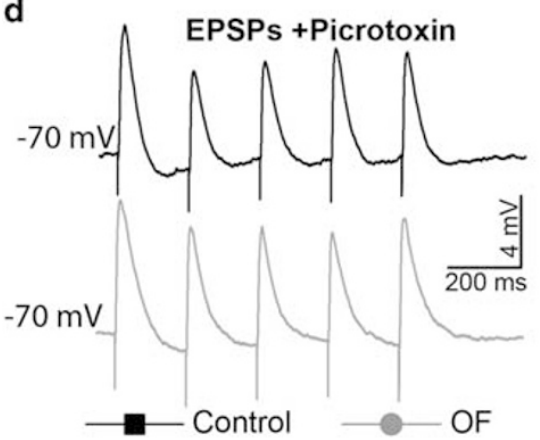

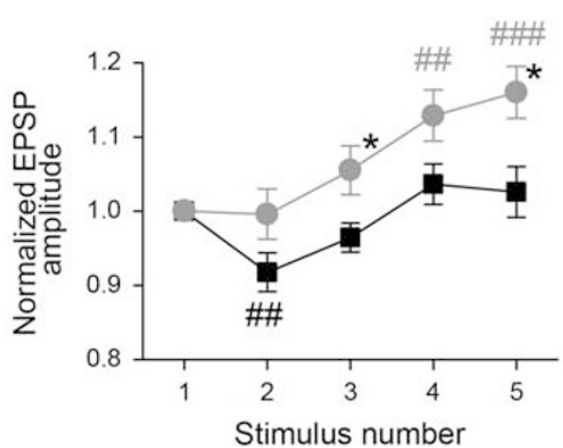

+ Picrotoxin

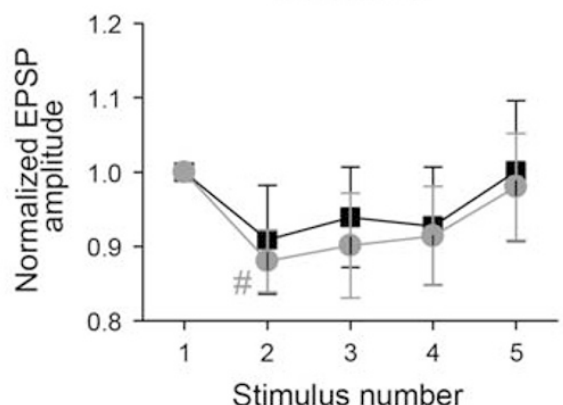

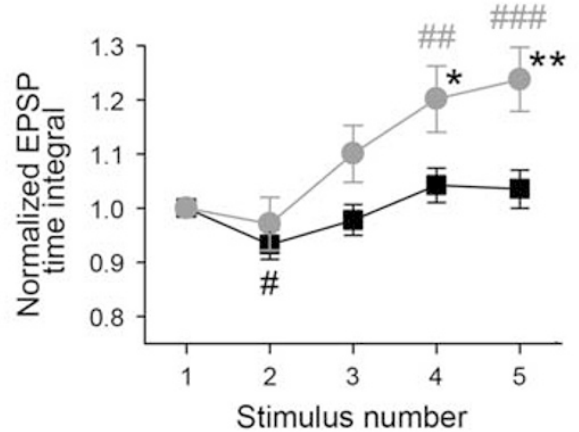

+ Picrotoxin

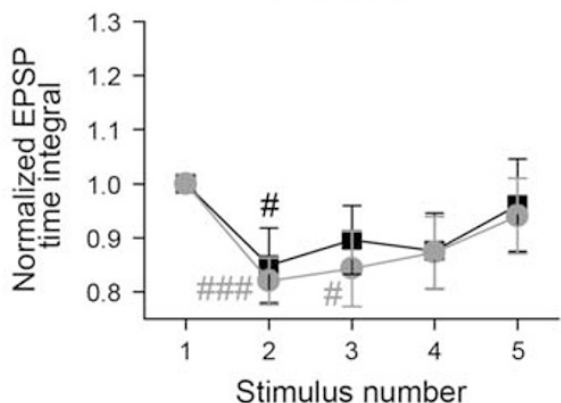

Figure I Observational fear training (OF) increases excitability of dorso-medial prefrontal cortex (dmPFC) layer $V$ principal neurons and enhances facilitation of EPSPs evoked by a $5 \mathrm{~Hz}$ train of electrical stimuli. (a) Experimental scheme. Stimulation of dmPFC layer I and recording from principal neurons in layer $\mathrm{V}$ are illustrated. (b) Left: examples of responses to AP threshold stimulation with $5 \mathrm{~Hz}$ train in control (upper, black) and OF group (lower, gray). Right; firing probabilities at each stimulus and across five stimuli (total), control (black): 10 cells/3 mice, OF (gray): 9 cells/3 mice. (c) Left: examples of EPSPs evoked by AP subthreshold stimulation, averages of 5 sweeps are shown. Right: EPSP amplitudes and time integrals normalized to the values of the first EPSP, control: 18 cells/3 mice, OF: 22 cells/3 mice. (d) Same experiment as in c, but in the presence of picrotoxin (I 00 HM), control: 9 cells/3 mice, OF: 9 cells/3 mice. OF vs control: ${ }^{*} p<0.05$ and ${ }^{*} * x<0.01$; intragroup comparison to the first pulse responses: ${ }^{\#} p<0.01$, ${ }^{\# \#} p<0.01$, and ${ }^{\# \# \#} p<0.00$ I. Error bars represent s.e.m.

electrical pulses and evoked postsynaptic responses were recorded from layer V PCs (Figure 1a) maintained at $-70 \mathrm{mV}$ in current clamp mode. To examine the susceptibility of neurons to generating action potentials in response to the repeated stimulation, stimulus intensity was set to elicit EPSPs of about $20 \mathrm{mV}$ by the first pulse in the train, which brought membrane potential to $-50 \mathrm{mV}$, near the action potential threshold. In response to the first pulse in the train, neurons from the OF group mice showed a tendency, although nonsignificant $(p>0.05)$, of having a higher probability of firing action potential than neurons from the control group mice. The probability became significantly higher during the second through the fifth pulses of the train $(p<0.01$, collapsed data for stimuli 2-5)
(Figure 1b). We next examined the EPSP dynamics along the train of stimuli adjusted to obtain the first EPSP at 4 to $10 \mathrm{mV}$, which was below the threshold for the action potential. In the control group, the amplitude and time integral of the second EPSP were significantly lower than those of the first EPSP (amplitude: $p<0.01$, time integral: $p<0.05)$, whereas the values for the third to fifth EPSPs were the same $(p>0.05)$. In contrast, in the OF group, the second EPSP did not differ from the first one $(p>0.05)$, whereas the values for the fourth and fifth EPSPs were significantly higher (amplitude and time integral, fourth: $p<0.01$; fifth: $p<0.001)$. As a result, the amplitudes of the third $(p<0.05)$ and fifth $(p<0.05)$ EPSPs and the time integrals of the fifth $(p<0.05)$ and fifth $(p<0.01)$ EPSPs were higher in the OF 
than in control group (Figure 1c). Including GABAa receptor blocker picrotoxin $(100 \mu \mathrm{M})$ in the bath prevented the facilitation of the fourth and fifth EPSP in the OF group $(p>0.05$, amplitudes and time integrals compared to the values for the first EPSP) and abolished the differences between $\mathrm{OF}$ and control groups in the third through fifth EPSPs $(p>0.05)$ (Figure 1d), suggesting that the OF effects on EPSPs resulted from changes in GABAergic transmission.

\section{OF Training Enhances Depression of IPSCs Recorded from the Soma}

Evoked IPSCs were elicited in L5 PCs, voltage clamped at $0 \mathrm{mV}$, using the same electrode placement and stimulus pattern as in Figure 1, except the stimulus intensity, was adjusted to obtain the first IPSC within 400 to $1200 \mathrm{pA}$ range. Both the IPSC amplitudes and charge transfer decreased along the train in all cells (amplitude: control, $\mathrm{F}(4,20)=53.2$, $p<0.001$; OF, $\mathrm{F}(4,19)=190, p<0.0001$; charge transfer: control, $\mathrm{F}(4,20)=164, \quad p<0.001 ; \quad \mathrm{OF}, \quad \mathrm{F}(4,19)=294$, $p<0.0001$, repeated measure ANOVA) with greatest decreases occurring between the first and second IPSCs. The IPSC depression was stronger in OF group than in controls (behavioral treatment ${ }^{\star}$ amplitude interaction: $\mathrm{F}(4,39)=5.9$, $p<0.001$; behavioral treatment ${ }^{*}$ charge transfer interaction $\mathrm{F}(4,39)=4.5, p<0.01)$, resulting in lower values for the second through fifth IPSCs in OF group (amplitude: $p<0.01$ or $<0.001$; charge: $p<0.05$ or $<0.01$ ) (Figure 2a). As $\mathrm{GABAb}$ auto-receptor contributes to IPSC depression in the neocortex (Fukuda et al, 1993; Kobayashi et al, 2012), we repeated the experiment in the presence of GABAb receptor (GABAbR) blocker CGP52432 in the bath $(10 \mu \mathrm{M})$. CGP52432 significantly attenuated the IPSC depression along the train in OF group (CGP52432* IPSC amplitude interaction: $\quad \mathrm{F}(4,33)=14.6, \quad p<0.0001 ; \quad$ CGP52432* IPSC charge interaction $\mathrm{F}(4,33)=25.2, p<0.0001)$, thereby eliminating the differences between the control and OF groups in IPSC dynamics (behavioral treatment ${ }^{\star}$ amplitude interaction: $\mathrm{F}(4,28)=1.7, p>0.05$; behavioral treatment ${ }^{*}$ charge transfer interaction $F(4,28)=1.5, p>0.05)$, and in the second through fifth IPSCs' amplitudes and charge transfers $(p>0.05)$ (Figure $2 \mathrm{~b})$, which suggests that the effects of OF on IPSC dynamics are mediated by changes in a GABAbRdependent process.

\section{CGP52432 and Evoked Excitation}

To determine how GABAbR regulates the evoked action potentials and EPSPs, the same experiments as in Figures $1 \mathrm{~b}$ and $c$ were performed first in the absence and then after 10 min perfusion with $10 \mu \mathrm{M}$ CGP52432 (Figure 3). In the absence of CGP52432, the OF group showed a higher probability of total firing $(p<0.01)$ than the controls, reproducing the findings on Figure 1b. Bath application of CGP52432 increased the firing probabilities in both groups during the entire train and upon stimuli 2 through 5 $(p<0.05)$ (Figure $3 \mathrm{~b})$, thereby eliminating the differences between the groups. Two-way repeated measure ANOVA showed significant interaction between behavioral treatment and CGP52432 for total firing probability $(\mathrm{F}(1,15)=8.7$,

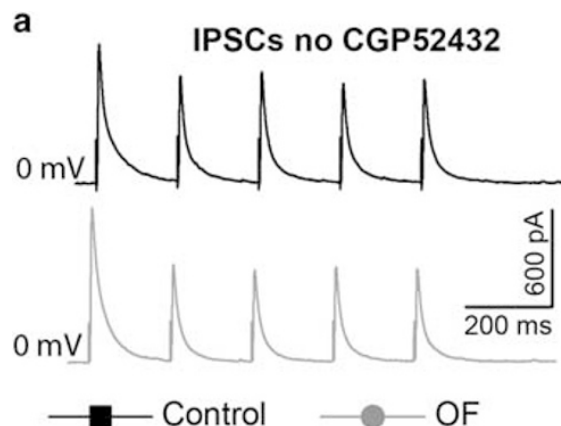

b

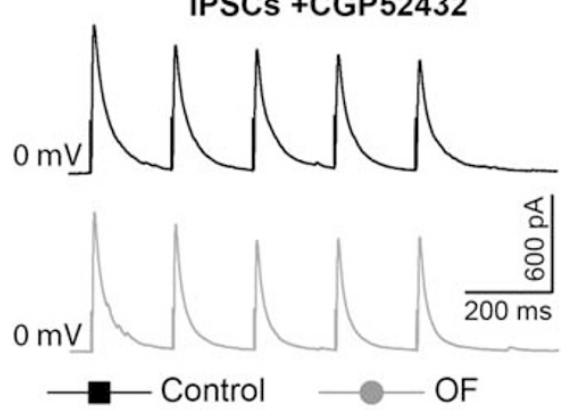

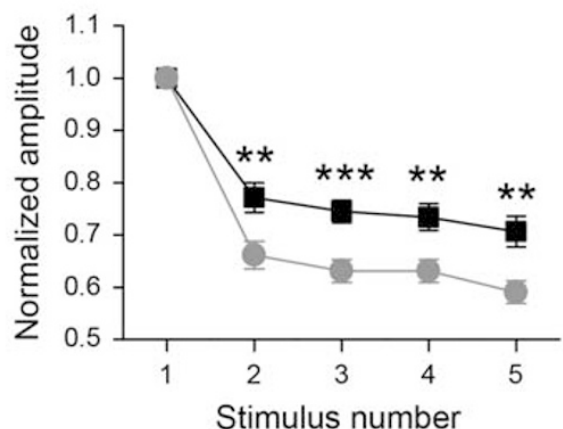

Stimulus number

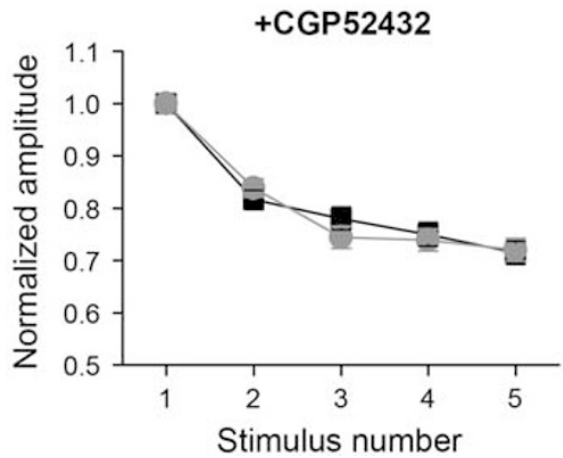

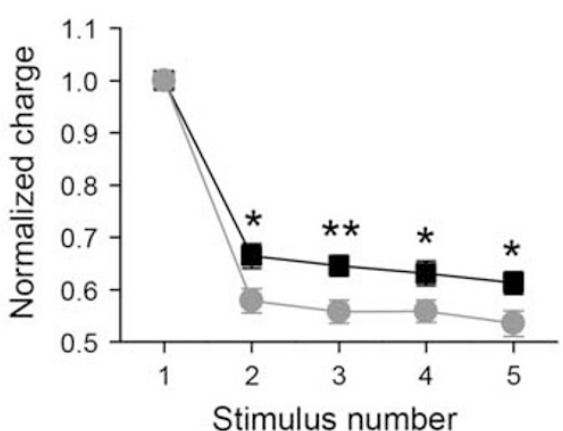

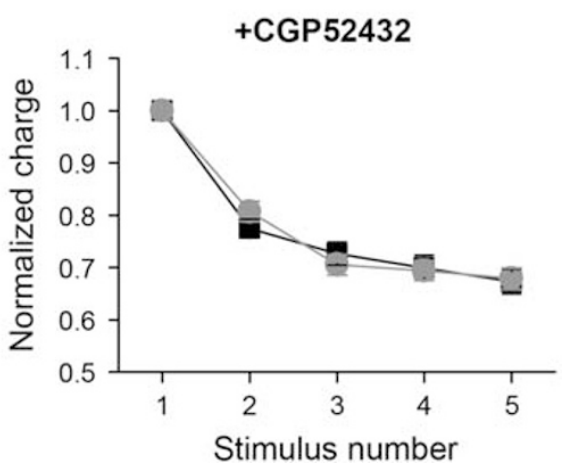

Figure 2 Observational fear training (OF) enhances depression of somatic inhibitory postsynaptic currents (IPSCs). (a) Left: examples of IPSCs evoked in L5 pyramidal cells (PCs) held at $0 \mathrm{mV}$ by $5 \mathrm{~Hz}$ train of electrical pulses delivered in LI, averages of five sweeps are shown. Right: IPSC amplitudes and charge transfers normalized to the values of the first IPSC, control: 21 cells/3 mice; OF: 20 cells/3 mice. (b). Same experiment as in a, in the presence of CGP52432 $($ I 0 MM), control: I 5 cells/3 mice; OF: I 5 cells/3 mice. Black and gray colors represent control and OF groups, respectively. OF vs control: $* p<0.05$, *** $p<0.01$, and ${ }^{* * * *} p<0.001$. Error bars represent SEM. 

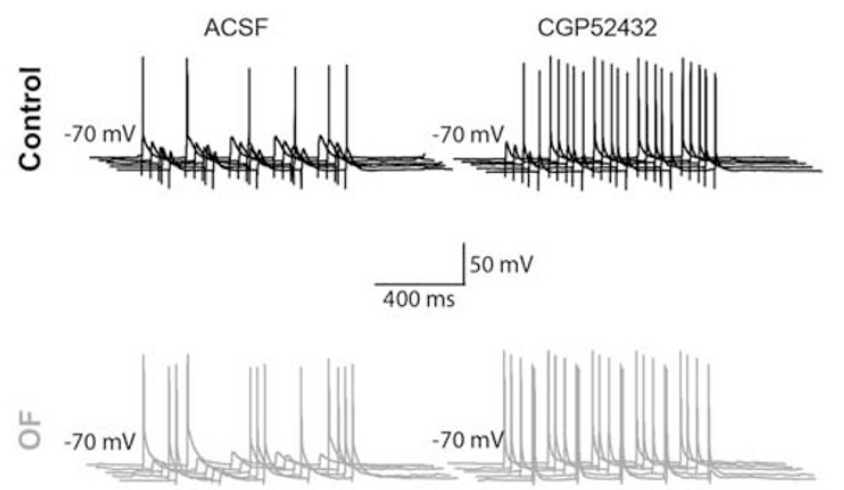
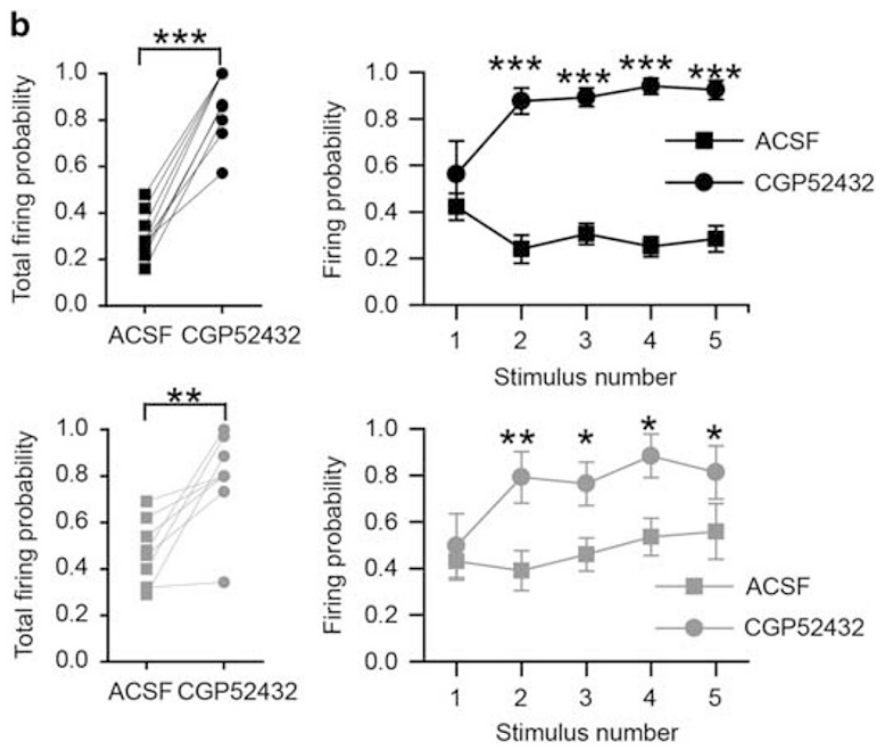

C

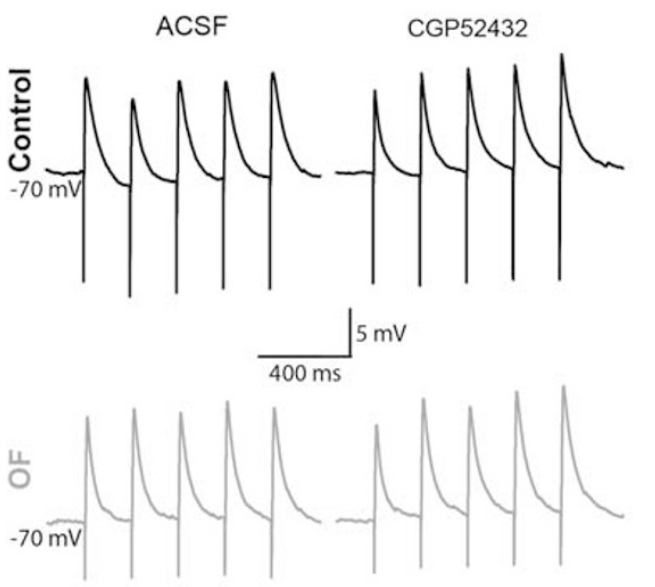

d

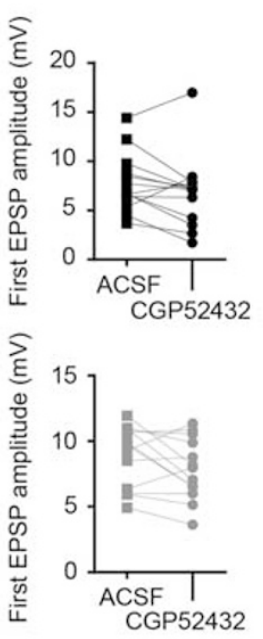

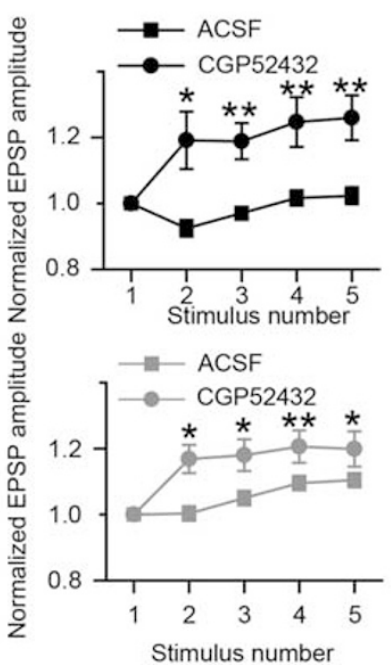

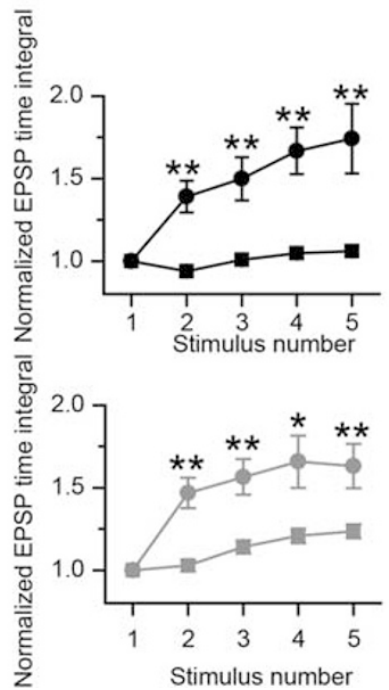

Figure 3 Effects of CGP52432 on evoked excitation. (a) Examples of responses to AP threshold stimulation with $5 \mathrm{~Hz}$ train in control (upper) and observational fear (OF) group (lower) before (left, ACSF), and after (right, CGP52432) perfusion with CGP52432. (b) Right: firing probabilities during the entire train (left: data for individual cells) and upon each stimulus in control (upper): nine cells/three mice and OF (lower): eight cells/three mice. (c) Left: examples of EPSPs evoked by AP subthreshold stimulation in control (upper) and OF group (lower) in the same cells before (left, ACSF) and after (right, CGP52432) perfusion with CGP52432. Averages of five sweeps are shown. (d) Left: Amplitudes of the first EPSPs in the train before and after perfusion with CGP52432, lines connect data points representing the same cells. Right: EPSP amplitudes and time integrals normalized to the values of the first EPSP, before and after perfusion with CGP52432; control: I 3 cells/3 mice, OF: I 3 cells/3 mice. ASCF vs CGP52432: * $p<0.05$, ** $p<0.0$ I, and **** $p<0.00$ I. Black and gray colors represent control and OF groups, respectively. Error bars represent SEM.

$p=0.01)$ and for firing probabilities upon stimuli 3 $(\mathrm{F}(1,15)=6.5, p=0.02), 4(\mathrm{~F}(1,15)=10.4, p=0.006)$ and 5 $(\mathrm{F}(1,15)=11.3, p=0.004)$. It indicated that the enhancing effect of CGP52432 was weaker in the OF group, likely due to the higher initial firing in the absence of CGP52432. In the subthreshold EPSP experiments, CGP52432 did not change the amplitudes of the first EPSP significantly despite of tendencies to decreases, but enabled facilitation between the first and second EPSPs in both groups (EPSP amplitudes, $p<0.05$; EPSP time integral, $p<0.001$, paired $t$-test) (Figure 3d), which eliminated the differences in EPSC dynamics between the groups described in Figure 1c.

\section{OF Training Attenuates IPSC Depression at Distal Dendrites}

Because of the dendritic filtering and poor space clamp at distal dendrites, the outward currents recorded in the soma represent the IPSCs originating mainly from the soma and proximal dendrites (Williams and Mitchell, 2008). To enrich recording for IPSCs originating from distal dendrites, we suppressed GABAa receptor on the soma and proximal dendrites by puffing picrotoxin on the soma of the recorded neuron (Figure 4a). Picrotoxin continued to inhibit GABAa receptor after puffing was over, as indicated by a significant reduction in frequencies (normalized frequency: $p<0.0001$, comparison to $100 \%$ baseline, one sample $t$-test) and 
a

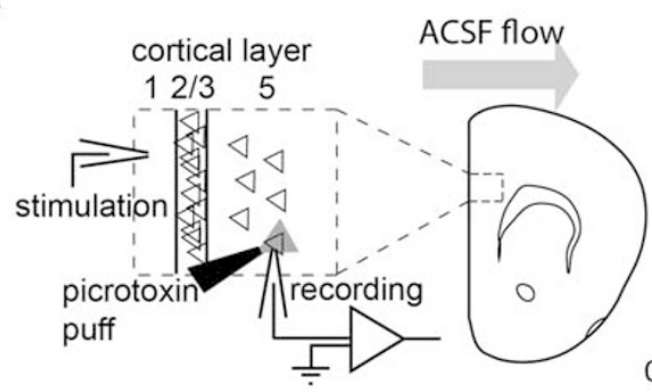

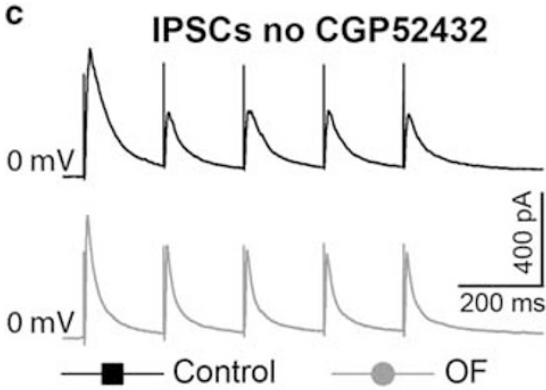

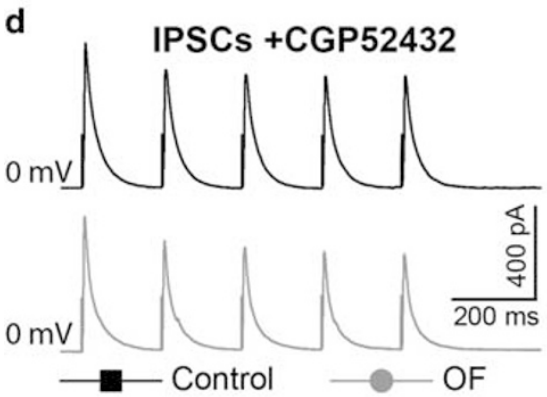

。 b
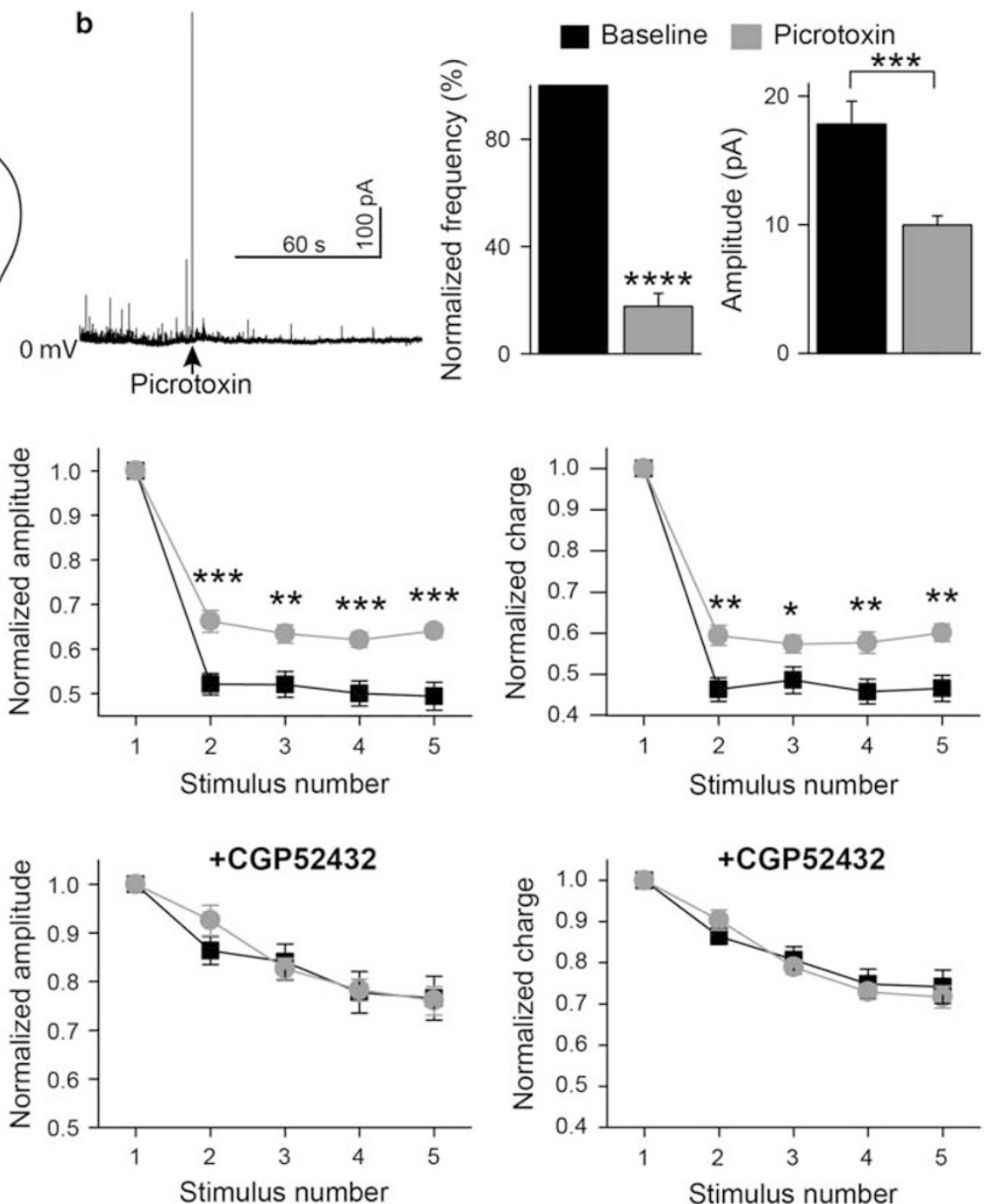

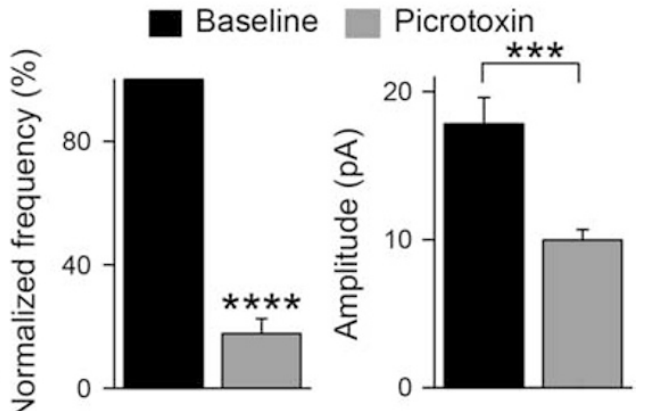

Figure 4 Observational fear training (OF) attenuates depression of dendritic inhibitory postsynaptic currents (IPSCs). (a) Experimental scheme. Stimulation of dmPFC layer I, voltage-clamp recording from the layer $\mathrm{V}$ principal neuron held at $0 \mathrm{mV}$ and puffing picrotoxin on soma of the recorded neuron are illustrated. Directions of puffing and ASCF flow are shown. (b). Picrotoxin puff on soma eliminated above $80 \%$ of spontaneous IPSCs (sIPSCs) and decreased sIPSC amplitude. Left: an example of sIPSC recorded before and after a somatic puff of picrotoxin. Right: summary data for sIPSCs detected within I min before (Baseline) and after (Picrotoxin) puff of picrotoxin (I mM): sIPSC frequency normalized to the baseline value and absolute amplitude. Data were merged from control and OF groups, six cells/three mice each, as picrotoxin effects were same between the groups. (c) Left: examples of IPSCs evoked by $5 \mathrm{~Hz}$ train of electrical pulses, averages of five sweeps are shown. Right: IPSC amplitudes and charge transfers normalized to the values of the first IPSC, control: I I cells/3 mice, OF: 12 cells/3 mice. (d) Same experiment as in c, in the presence of CGP52432 ( I 0 HM), control: I 5 cells/3 mice, OF: I 5 cells/3 mice. Black and gray colors represent control and OF groups, respectively. Baseline vs Picrotoxin, or OF vs control: $* p<0.05, * * 2<0.01, * * * p<0.001$, and ******* $<<0.000$ I. Error bars represent SEM.

amplitudes ( $p=0.001$, unpaired $t$-test) of spontaneous IPSC (Figure $4 \mathrm{~b}$ ). In picrotoxin-puffed neurons, evoked IPSCs were depressed along the train in both control and $\mathrm{OF}$ groups (amplitude: control, $\mathrm{F}(4,10)=208, p<0.0001$; OF, F $(4,11)=176, \quad p<0.0001 ; \quad$ charge transfer: control, $F$ $(4,10)=224, p<0.0001 ; \mathrm{OF}, \mathrm{F}(4,11)=214, p<0.0001$, repeated measure ANOVA), mainly between the first and second IPSCs, resulting in higher normalized amplitudes and charge transfers for the second through fifth IPSCs in OF group (amplitude: $p<0.01$ or $<0.001$; charge: $p<0.05$ or $<0.01$ ) (Figure 4c). Surprisingly, in contrast to the experiment without puffing picrotoxin (Figure 2a), OF attenuated the depression of IPSC along the train (behavioral treatment*amplitude interaction: $\mathrm{F}(4,21)=9.5, \quad p<0.0001$; behavioral treatment ${ }^{\star}$ charge transfer interaction $\mathrm{F}$ $(4,21)=7.7, p<0.0001)$. CGP52432 significantly attenuated the IPSC depression along the train in both the control and OF groups (control, CGP52432*IPSC amplitude interaction: $\mathrm{F}(4,24)=37.7, p<0.0001$; CGP52432 ${ }^{\star}$ IPSC charge transfer interaction $\mathrm{F}(4,24)=38.0, p<0.0001$; OF, CGP52432* IPSC amplitude interaction: $\mathrm{F}(4,25)=15.2, \quad p<0.0001 ; \quad$ and CGP52432 $*$ IPSC charge transfer interaction $\mathrm{F}(4,25)=21.8$, $p<0.0001$ ), and abolished the differences between the control and OF groups in IPSC dynamics (behavioral treatment ${ }^{*}$ IPSC amplitude interaction: $\mathrm{F}(4,28)=1.7$, $p>0.05$; behavioral treatment ${ }^{\star}$ IPSC charge transfer interaction $\mathrm{F}(4,28)=1.5, p>0.05)$, and in the second through fifth IPSCs' amplitudes and charge transfers $(p>0.05)$ 
a

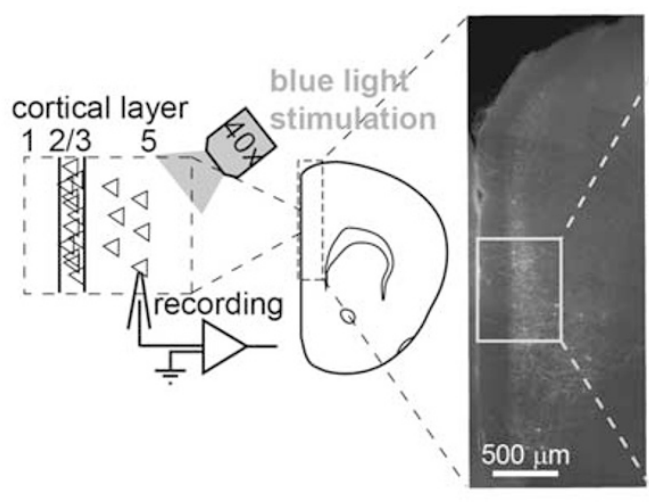

PV-ChR2-YFP

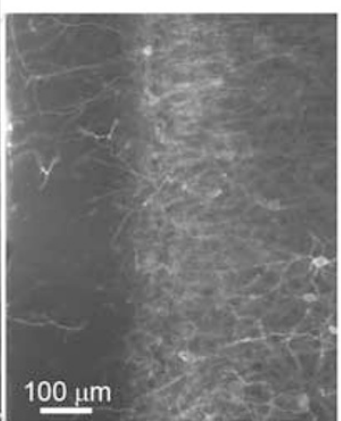

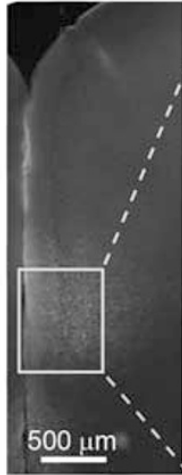

$\underline{\text { SOM-ChR2-YFP }}$
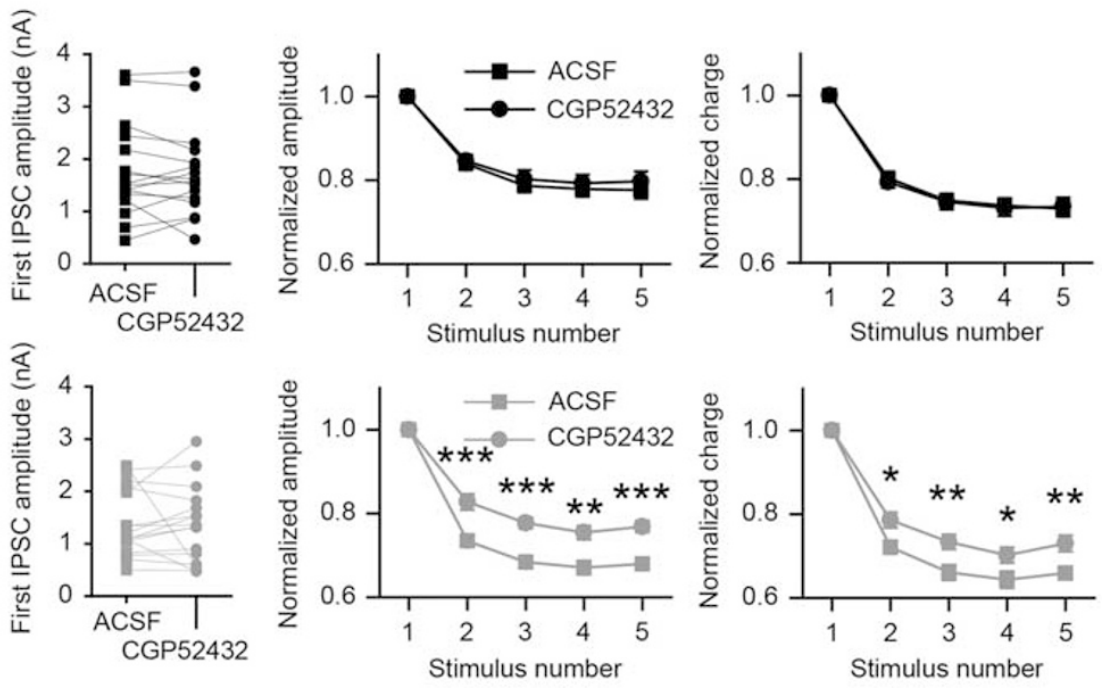

C SOM-ChR2-YFP
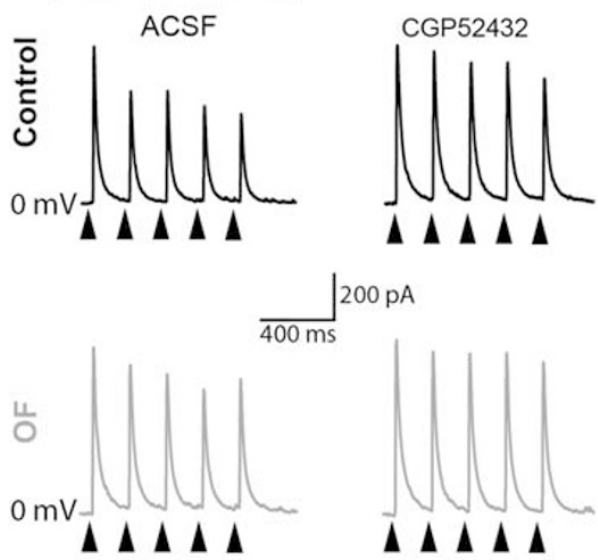

$200 \mathrm{pA}$
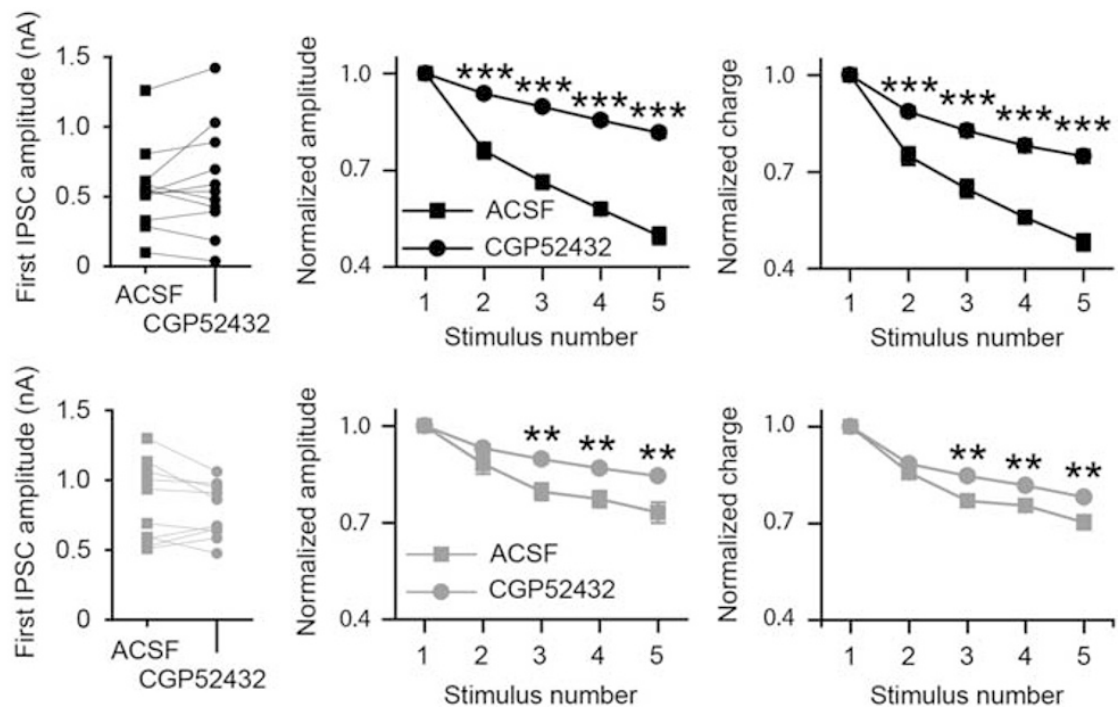

Figure 5 Observational fear training (OF) enhances depression of inhibitory postsynaptic currents (IPSCs) originating from parvalbumin (PV)-positive interneurons but suppresses that from somatostatin (SOM)-positive interneurons. (a) Left: experimental scheme. Stimulation of dmPFC with blue light and recording from principal neurons in layer $V$ are illustrated. Right: fluorescent microscope images of ChR2-YFP expressed in PV and SOM interneurons in dorso-medial prefrontal cortex (dmPFC) shown at low and high magnifications. The corresponding areas are marked by white rectangles. (b) Left: examples of IPSCs evoked in the same cells by $5 \mathrm{~Hz}$ train of blue light stimulation of PV-interneurons expressing ChR2 before and after perfusion with CGP52432 ( 0 HM), averages of five sweeps are shown. Arrowheads under each sweep show the time of stimulation. Middle: amplitudes of the first IPSCs in the train before and after perfusion with CGP52432, lines connect data points representing the same cells. Right: IPSCs amplitudes and time integrals normalized to the values of the first IPSC, before and after perfusion with CGP52432. Black and gray colors represent control (I6 cells/3 mice) and OF (I6 cells/3 mice) groups, respectively. (c) Same experiment as in (b), except ChR2, was expressed in SOM-INs. Control: I I cells/3 mice, OF: 10 cells/3 mice. ASCF vs CGP52432: $* p<0.05$, $* * * 0.01$, and $* * * * 00.001$. Error bars represent SEM. 
a PV-ChR2-YFP

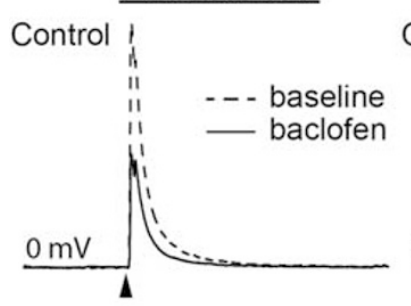

b SOM-ChR2-YFP

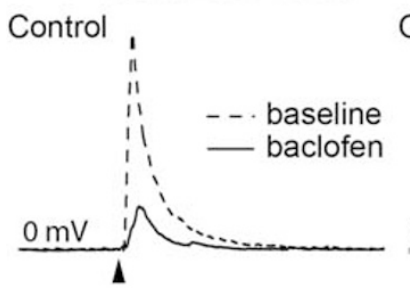

c
O PV/Control - PV/OF

$\triangle \mathrm{SOM} /$ Control $\quad \mathrm{SOM} / \mathrm{OF}$

baseline

- baclofen

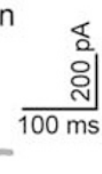

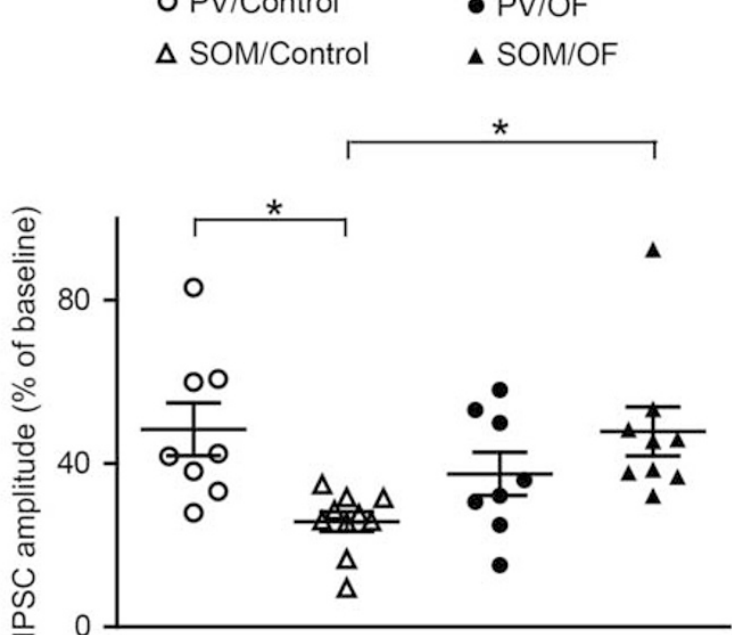

Figure 6 Observational fear training (OF) decreases sensitivity to baclofen in somatostatin (SOM) interneurons, but not in parvalbumin (PV) interneurons. (a) Examples of inhibitory postsynaptic currents (IPSCs) evoked in dorso-medial prefrontal cortex (dmPFC) principal neurons by a single pulse of blue light stimulation of PV-interneurons expressing ChR2, before (Baseline, dashed lines) and after 5 min exposure to $20 \mu M$ baclofen in the bath (Baclofen, continuous lines) in control (Control: eight cells/three mice) and OF (eight cells/three mice) groups. Averages of I0 sweeps are shown. Arrowheads under each sweep show the time of blue light stimulation. (b) Same as in a for blue light stimulation of SOM interneurons expressing ChR2. Control: I 0 cells/3 mice; OF: 9 cells/3 mice. (c) Summary diagram for amplitudes of IPSCs in the presence of baclofen as \% of values before baclofen perfusion. * $p<0.05$. Error bars represent SEM.

(Figure 4d), which suggests that GABAbR also mediates effects of OF on the dynamics of evoked IPSC originating from distal dendrites.

\section{OF Training has Opposing Effects on Inputs from PV- and SOM-INs}

Inhibitory inputs in soma and distal dendrites of cortical neurons are preferentially formed by the PV and SOM interneurons, respectively (Freund and Buzsaki, 1996; Markram et al, 2004; Petilla Interneuron Nomenclature et al, 2008). To examine effects of OF on these inputs and role of GABAb receptors, we recorded IPSCs evoked in the layer V PCs by blue light stimulation of either PV-INs (PV-IPSCs) or SOM-INs (SOM-IPSCs) expressing channelrhodopsin-2 (Figure 5a). IPSCs from the same neurons were recorded in the absence and then in the presence of CGP52432, which did not change the amplitude of the first SOM-IPSCs and PV-IPSCs in the trains (Figures $5 \mathrm{~b}$ and $\mathrm{c}$, middle).

The PV-IPSC amplitudes and charge transfer decreased along the train in both control and OF groups (amplitude: control, $\quad \mathrm{F}(4,15)=111, \quad p<0.0001 ; \quad \mathrm{OF}, \quad \mathrm{F}(4,15)=221$, $p<0.0001$; charge transfer: control, $\mathrm{F}(4,15)=166, p<0.0001$; OF, $\mathrm{F}(4,15)=222, p<0.0001$, repeated measure ANOVA), but the IPSC depression was stronger in OF group than in controls (behavioral treatment ${ }^{*}$ amplitude interaction: $\mathrm{F}(4,30)=12.5, p<0.0001$; behavioral treatment ${ }^{*}$ charge transfer interaction $F(4,30)=8.2, p<0.0001)$. CGP52432 had no significant effect on IPSC depression in controls (CGP52432 $\star$ IPSC amplitude interaction: $\mathrm{F}(4,30)=0.35$, $p=0.84$; CGP52432*IPSC charge interaction $\mathrm{F}(4,30)=0.17$, $p=0.95)$, but attenuated IPSC depression in the OF group (CGP52432*IPSC amplitude interaction: $\mathrm{F}(4,30)=9.1$, $p<0.0001$; CGP52432 ${ }^{\star}$ IPSC charge interaction $\mathrm{F}(4,30)=4.1$, $p=0.004)$ (Figure 5b right), thereby eliminating the differences between the control and OF groups in IPSC dynamics (behavioral treatment ${ }^{\star}$ amplitude interaction: $\mathrm{F}(4,30)=1.0$, $p=0.4$; behavioral treatment ${ }^{*}$ charge transfer interaction $\mathrm{F}(4,30)=0.6, p=0.7)$.

The SOM-IPSC amplitudes and charge transfers also decreased along the train in both control and OF groups (amplitude: control, $\mathrm{F}(4,10)=121, p<0.0001 ; \mathrm{OF}, \mathrm{F}(4,9)=38$, $p<0.0001$; charge transfer: control, $\mathrm{F}(4,10)=127, p<0.0001$; OF, $\mathrm{F}(4,9)=103, p<0.0001$, repeated measure ANOVA); however, in contrast to its effect on PV-IPSCs, OF attenuated the depression of SOM-IPSC (behavioral treatment ${ }^{*}$ amplitude interaction: $\mathrm{F}(4,19)=12.9, \quad p<0.0001$; behavioral treatment $^{\star}$ charge transfer interaction $\left.\mathrm{F}(4,19)=16, p<0.0001\right)$. CGP52432 attenuated SOM-IPSC depression in both, the control and OF groups (control, CGP52432*IPSC amplitude interaction: $\mathrm{F}(4,20)=39, p<0.0001$; CGP52432*IPSC charge interaction $\mathrm{F}(4,20)=24, \quad p<0.0001 ; \quad \mathrm{OF}, \quad$ CGP52432*IPSC amplitude interaction: $\mathrm{F}(4,18)=5.9, \quad p=0.0004 ; \quad$ and CGP52432 $*$ IPSC charge interaction: $\mathrm{F}(4,18)=209$, $p<0.0001)$ (Figure $5 c$ right), eliminating the differences between the groups in IPSC dynamics (behavioral treatmen$t^{\star}$ amplitude interaction: $\mathrm{F}(4,19)=1.2, p=0.32$; behavioral treatment ${ }^{*}$ charge transfer interaction $\left.\mathrm{F}(4,19)=1.8, p=0.14\right)$. These results suggested that GABAbR mediates effects of OF on the dynamics of evoked IPSCs from PV- and SOM-INs in the opposing manners.

\section{OF Training has a Different Effect on GABAbR Control of GABA Release from SOM- than PV-INs}

To quantify GABAbR-mediated inhibition of GABA release in inputs to the layer V PCs from PV and SOM neurons, we examined effects of a GABAbR agonist baclofen on PV-IPSCs and SOM-IPSCs either in controls or OF cells. 
Five-minute perfusion with $20 \mu \mathrm{M}$ baclofen significantly inhibited IPSCs in all four experimental groups (IPSC amplitude \% of baseline compared to $100, p<0.0001$ ) (Figure 6). One-way AVONA revealed significant differences among the four groups $(p<0.01)$. Bonferroni's multiple comparisons revealed significant differences between the $\mathrm{PV} /$ Control and SOM/Control $(p<0.05)$, between SOM/Control and SOM/OF $(p<0.05)$, but not between PV/Control and PV/OF groups. Two-way ANOVA revealed a significant 'IPSC type '*'behavioral treatment' interaction $(p<0.01)$ and Bonferroni posttest showed a significant effect of behavioral treatment on the SOM-IPSCs $(p<0.01)$, but not on the PV-IPSCs. Thus, under control conditions, GABAbR exerts stronger inhibition of GABA release from SOM-INs than from PV-INs but OF eliminates that difference by attenuating GABAbR suppression of GABA release from SOM-INs.

\section{DISCUSSION}

The key finding here is that the OF, one form of purely emotional distress in mice, reorganizes inhibition of dmPFC layer $\mathrm{V}$ pyramidal neurons by attenuating the GABAbR control of GABA release from SOM-INs, but not from PVINs, which underlie mainly dendritic and somatic inhibition, respectively. This study, however, does not rule out a possibility of such changes on exposure to other stressors. Furthermore, it remains to be determined whether the observed changes could be attributed to the contextual learning during OF (Jeon et al, 2010) or to the effect of trauma on future learning in the PA paradigm (Ito et al, 2015).

Imaging studies have demonstrated that traumatic events alter functional connectivity of the prefrontal cortex in humans (Krause-Utz et al, 2014; Lanius et al, 2010; Long et al, 2014; van Wingen et al, 2012) and rodents (Henckens et al, 2015; Liang et al, 2014), but synaptic process underlying such changes remains largely unexplored. To that end, we examined OF-induced synaptic adaptations in PCs in dmPFC layer $\mathrm{V}$, which are one of the major outputs of dmPFC. These cells can serve as a reporter of alterations in multiple microcircuits within dmPFC, because their dendrites span through all cortical layers and integrate inputs from remote and local afferents. We electrically stimulated dmPFC layer I, which contains axons arriving from cortex and thalamus, as well as local ascending glutamatergic and GABAergic axons. The $5 \mathrm{~Hz}$ stimulation frequency was selected as physiologically relevant, given the 'midline frontal theta' $3-7 \mathrm{~Hz}$ band correlation with working memory in humans (Gevins et al, 1997; Sauseng et al, 2010) and the predominance of the $2-5 \mathrm{~Hz}$ band in PFC of the rat (Fujisawa and Buzsaki, 2011).

\section{Dynamics of Excitation and Inhibition}

OF increased the likelihood of action potentials in PCs during the $5 \mathrm{~Hz}$ stimulation train, which was consistent with the emerged EPSP facilitation along that train. The EPSP facilitation was no longer seen in the presence of GABAa receptor blocker picrotoxin, which indicated that GABAergic transmission was essential for that facilitation. The stronger decline of evoked inhibition along the train may underlie the observed EPSP facilitation after OF.

\section{The Role of GABAbR}

Presynaptic GABAbR mediates short-term depression of GABAergic synapses during repeated stimulation in the somatosensory and insular cortex, particularly when the interval between stimuli is within 150-300 ms (Fukuda et al, 1993; Kobayashi et al, 2012). Surprisingly, in our preparation in the control group, a GABAbR blocker CGP52432 had no significant effect on IPSC depression. However, in the OF group, CGP52432 decreased the depression, thus abolishing effects of OF. It indicates that OF recruits GABAbR to enhance the IPSC depression, which is normally GABAbR independent. The observed effects of CGP52432 on IPSCs are unlikely to involve postsynaptic GABAbR, because QX314, which blocks GABAbR-mediated hyperpolarization (Andrade, 1991; McLean et al, 1996; Nathan et al, 1990), was included in the internal solution.

In the analyses of evoked excitation in the layer 5 principal cells, CGP52432 eliminated the differences between the OF and control groups in both firing and EPSP dynamics, which suggests that GABAbR is contributing to the effects of OF on evoked excitation. This contribution could involve GABAbR both in principal cells in interneurons because bath applied CGP52432 blocks GABAbR in all cells.

\section{Somatic $v s$ Dendritic Inhibition}

Given that somatic voltage clamp poorly controls voltage at distal dendrites (Williams and Mitchell, 2008), the somatically recorded IPSCs mainly represent synaptic events near the soma and can be considered as 'somatically enriched IPSCs'. Then, we enriched recordings for IPSCs originating from distal dendrites by puffing picrotoxin on the soma of recorded neurons. The properties of the 'dendritically enriched IPSCs' were different from those of the somatically enriched IPSCs. First, in the control group, they exhibited stronger depression, which was sensitive to CGP52432. Second, OF training rather attenuated their depression and decreased its sensitivity to CGP52432. These results indicate that $\mathrm{OF}$ attenuates GABAbR control over GABAergic inputs to distal dendrites, which is normally stronger than over inputs to soma. Through these opposing effects on GABAbR control of somatic $v s$ dendritic IPSC, OF training may equalize the dynamics of IPSC depression along the somatodendritic axis. Yet, our analysis does not distinguish between IPSCs originating at the soma vs proximal dendrites, because it remains unclear at what distance from the soma picrotoxin puff was blocking GABAa receptor.

\section{GABAbR-Dependent Alterations in PV-IN and SOM-IN Inputs to L5 PCs}

To identify cells that underlie the observed GABAbR control of GABA transmission, IPSCs originating from PV- and SOM-INs (PV-IPSCs and SOM-IPSCs, respectively) were isolated by blue light stimulation of interneurons expressing ChR2. The effects of OF training and GABAbR blocker CGP52432 on PV-IPSCs were very similar with their effects on 'somatically enriched' IPSCs evoked by electrical stimulation of dmPFC layer 1 in the absence of picrotoxin puff. Conversely, effects on SOM-IPSCs resembled those on 'dendritically enriched' IPSCs, which were evoked by the 
same electrical stimulation, but after picrotoxin puff to soma. Although electrical stimulation differs from the blue light stimulation by recruiting broader neuronal networks including several types of SOM-negative INs, such as the 5-HT receptor 3 expressing cells that target distal dendrites, and also GABAergic synapses between INs, such as the strong inputs from SOM-INs to PV-INs (Marlin and Carter, 2014; Pfeffer et al, 2013), these observations indicate that picrotoxin puffs to the soma successfully shift the origin of recorded IPSCs from the soma to distal dendrites, consistent with the preferential targeting of PC soma by PV-INs and distal dendrites by SOM-INs, respectively (Freund and Buzsaki, 1996; Markram et al, 2004; Petilla Interneuron Nomenclature et al, 2008).

The strong modulation by GABAbR appears to be a distinct property of SOM-INs. In controls, CGP52432 strongly attenuated the depression of SOM-IPSCs (Figure 4c), but barely affected the depression of PV-IPSCs (Figure 4b), indicating that GABAbR control of SOM-INs is stronger than of PV-INs. This was consistent with the greater sensitivity to baclofen of the SOM-IPSCs than the PV-IPSCs in control mice, suggesting that SOM-INs naturally express more functional GABAbR, which agrees with an earlier finding in the hippocampus that SOM-INs have stronger GABAbR1 immunoreactivity than all other cells (Sloviter et al, 1999). The cell-type specific differences in GABAbR function could be an adaptation to possibly different local concentrations of GABA, high at perisomatic basket-type synapses and low at sparse dendritic synapses.

The attenuation of GABAbR-mediated depression of SOM-IPSCs after OF training is readily explained by decreased GABAbR function in SOM-INs, detected as decreased sensitivity of SOM-IPSCs to baclofen (Figure 5). Paradoxically, despite OF training enhanced the GABAbRmediated depression of PV-IPSCs, there was only a trend towards higher sensitivity of PV-IPSCs to baclofen. This discrepancy may reflect distinct modulation of GABAbR in each subcellular domain: the $5 \mathrm{~Hz}$ stimulation is expected to activate GABAbRs mostly near GABAergic terminals; whereas bath applied baclofen activates all receptors including those on soma and dendrites. The somatic and dendritic receptors can attenuate GABA release by preventing action potentials and thereby mask the effect from GABAbR upregulation at terminals after $\mathrm{OF}$ training.

The finding of altered GABAbR function one day after OF indicates long-term changes in either the receptor or its downstream targets. The possible mechanisms may involve NMDA receptor, which often participates in long-lasting plastic changes and has been shown to control trafficking and surface expression of GABAbR via the CaMKII-AMPK phosphorylation cascade (Guetg et al, 2010; Maier et al, 2010; Terunuma et al, 2010). Changing GABAbR kinetics properties by the KCTD family of axillary proteins (Gassmann and Bettler, 2012; Schwenk et al, 2010) or modulation via several recently discovered interacting proteins (Schwenk et al, 2016) may also be involved. Some of these mechanisms have been documented in dendrites of glutamatergic neurons but remain to be tested in GABAergic terminals. Understanding what underlies opposing regulation of GABAbR in PV- and SOM-INs may reveal the individual role of these cells during brain response to stress.

\section{Rerouting Information Flows in $\mathrm{dmPFC}$ as a Possible Functional Implication}

We found $\mathrm{OF}$ to rebalance inhibitory drive along the somatodendritic axis by changing GABAbR function in opposing ways in PV-INs for perisomatic inhibition and in SOM-INs for dendritic inhibition. As GABA transmission competes with glutamatergic inputs at dendrites by suppressing calcium spike (Perez-Garci et al, 2006) and local dendritic depolarization, which determines the direction of synaptic plasticity towards LTP or LTD (Sjostrom and Hausser, 2006), the OF training may reroute information flow across dmPFC by attenuating glutamatergic inputs to distal parts of dendrites, but enhancing inputs to soma and proximal dendrites. For intra-dmPFC communication, $\mathrm{OF}$ is expected to enhance connectivity among L5 PCs, because they receive inputs from one another mainly in the proximal basal dendritic tree (Markram et al, 1997), but to weaken those connections of layer $2 / 3$ neurons, which synapse on apical dendrites of layer 5 PCs (Thomson and Bannister, 1998). For the remote connectivity, OF is expected to attenuate corticocortical and thalamocortical inputs that target layer I of dmPFC, but to strengthen communication with areas such as the hippocampus and basolateral amygdala that send abundant projections to the deep layers (Cruikshank et al, 2010; Hoover and Vertes, 2007; Jay and Witter, 1991; Oh et al, 2014). The consequences can be even more interesting and complex. Studies in the hippocampus revealed that during synchronous activity, different classes of INs exhibit different firing patterns during different behavioral states and associated forms of oscillations (Klausberger et al, 2003). Furthermore, INs targeting different subcellular domains fire at different phases of the oscillation cycle (Klausberger and Somogyi, 2008), which was proposed to cause temporal redistribution of inhibition along the somatodendritic axis of PCs and thereby to maintain or segregate cell assemblies (Somogyi et al, 2014). By modifying that process, OF may contribute to either formation or dissolution of cell assemblies between L5 PC and remote neurons, depending on the somatodendritic location of their inputs to L5 PCs, and also, on the behavioral state and the corresponding pattern of oscillatory activity.

\section{FUNDING AND DISCLOSURE}

The authors declare no conflict of interest.

\section{ACKNOWLEDGMENTS}

This research was supported by VTCRI, Whitehall Foundation and NIMH grant R21MH112093.

\section{REFERENCES}

Andrade R (1991). Blockade of neurotransmitter-activated K+ conductance by QX-314 in the rat hippocampus. Eur J Pharmacol 199: 259-262.

Bero AW, Meng J, Cho S, Shen AH, Canter RG, Ericsson M et al (2014). Early remodeling of the neocortex upon episodic memory encoding. Proc Natl Acad Sci USA 111: 11852-11857.

Chen Q, Panksepp JB, Lahvis GP (2009). Empathy is moderated by genetic background in mice. PLOS ONE 4: e4387. 
Cougle JR, Resnick H, Kilpatrick DG (2009). Does prior exposure to interpersonal violence increase risk of PTSD following subsequent exposure? Behav Res Ther 47: 1012-1017.

Cruikshank SJ, Urabe H, Nurmikko AV, Connors BW (2010). Pathway-specific feedforward circuits between thalamus and neocortex revealed by selective optical stimulation of axons. Neuron 65: 230-245.

Freund TF, Buzsaki G (1996). Interneurons of the hippocampus. Hippocampus 6: 347-470.

Fujisawa S, Buzsaki G (2011). A $4 \mathrm{~Hz}$ oscillation adaptively synchronizes prefrontal, VTA, and hippocampal activities. Neuron 72: 153-165.

Fukuda A, Mody I, Prince DA (1993). Differential ontogenesis of presynaptic and postsynaptic GABAB inhibition in rat somatosensory cortex. J Neurophysiol 70: 448-452.

Gabbott PL, Warner TA, Jays PR, Salway P, Busby SJ (2005). Prefrontal cortex in the rat: projections to subcortical autonomic, motor, and limbic centers. J Compar Neurol 492: 145-177.

Gassmann M, Bettler B (2012). Regulation of neuronal GABA(B) receptor functions by subunit composition. Nat Rev Neurosci 13: 380-394.

Gevins A, Smith ME, McEvoy L, Yu D (1997). High-resolution EEG mapping of cortical activation related to working memory: effects of task difficulty, type of processing, and practice. Cereb Cortex 7: 374-385.

Guetg N, Abdel Aziz S, Holbro N, Turecek R, Rose T, Seddik R et al (2010). NMDA receptor-dependent GABAB receptor internalization via CaMKII phosphorylation of serine 867 in GABAB1. Proc Natl Acad Sci USA 107: 13924-13929.

Henckens MJ, van der Marel K, van der Toorn A, Pillai AG, Fernandez G, Dijkhuizen RM et al (2015). Stress-induced alterations in large-scale functional networks of the rodent brain. Neuroimage 105: 312-322.

Hippenmeyer S, Vrieseling E, Sigrist M, Portmann T, Laengle C, Ladle DR et al (2005). A developmental switch in the response of DRG neurons to ETS transcription factor signaling. PLoS Biol 3: e159.

Hirai Y, Morishima M, Karube F, Kawaguchi Y (2012). Specialized cortical subnetworks differentially connect frontal cortex to parahippocampal areas. J Neurosci 32: 1898-1913.

Hoover WB, Vertes RP (2007). Anatomical analysis of afferent projections to the medial prefrontal cortex in the rat. Brain Struct Funct 212: 149-179.

Ito W, Erisir A, Morozov A (2015). Observation of distressed conspecific as a model of emotional trauma generates silent synapses in the prefrontal-amygdala pathway and enhances fear learning, but ketamine abolishes those effects. Neuropsychopharmacology 40: 2536-2545.

Jay TM, Witter MP (1991). Distribution of hippocampal CA1 and subicular efferents in the prefrontal cortex of the rat studied by means of anterograde transport of Phaseolus vulgarisleucoagglutinin. J Compar Neurol 313: 574-586.

Jeon D, Kim S, Chetana M, Jo D, Ruley HE, Lin SY et al (2010). Observational fear learning involves affective pain system and Cav1.2 Ca2+ channels in ACC. Nat Neurosci 13: 482-488.

Kim D, Jeong H, Lee J, Ghim JW, Her ES, Lee SH et al (2016). Distinct roles of parvalbumin- and somatostatin-expressing interneurons in working memory. Neuron 92: 902-915.

Klausberger T, Magill PJ, Marton LF, Roberts JD, Cobden PM, Buzsaki G et al (2003). Brain-state- and cell-type-specific firing of hippocampal interneurons in vivo. Nature 421: 844-848.

Klausberger T, Somogyi P (2008). Neuronal diversity and temporal dynamics: the unity of hippocampal circuit operations. Science 321: 53-57.

Kobayashi M, Takei H, Yamamoto K, Hatanaka H, Koshikawa N (2012). Kinetics of GABAB autoreceptor-mediated suppression of GABA release in rat insular cortex. J Neurophysiol 107: 1431-1442.

Krause-Utz A, Elzinga BM, Oei NY, Paret C, Niedtfeld I, Spinhoven $\mathrm{P}$ et al (2014). Amygdala and dorsal anterior cingulate connectivity during an emotional working memory task in borderline personality disorder patients with interpersonal trauma history. Front Hum Neurosci 8: 848.

Lanius RA, Bluhm RL, Coupland NJ, Hegadoren KM, Rowe B, Theberge J et al (2010). Default mode network connectivity as a predictor of post-traumatic stress disorder symptom severity in acutely traumatized subjects. Acta Psych Scand 121: 33-40.

Liang Z, King J, Zhang N (2014). Neuroplasticity to a single-episode traumatic stress revealed by resting-state fMRI in awake rats. Neuroimage 103: 485-491.

Long J, Huang X, Liao Y, Hu X, Hu J, Lui S et al (2014). Prediction of post-earthquake depressive and anxiety symptoms: a longitudinal resting-state fMRI study. Sci Rep 4: 6423.

Maier PJ, Marin I, Grampp T, Sommer A, Benke D (2010). Sustained glutamate receptor activation down-regulates GABAB receptors by shifting the balance from recycling to lysosomal degradation. J Biol Chem 285: 35606-35614.

Malin EL, Ibrahim DY, Tu JW, McGaugh JL (2007). Involvement of the rostral anterior cingulate cortex in consolidation of inhibitory avoidance memory: interaction with the basolateral amygdala. Neurobiol Learn Mem 87: 295-302.

Malin EL, McGaugh JL (2006). Differential involvement of the hippocampus, anterior cingulate cortex, and basolateral amygdala in memory for context and footshock. Proc Natl Acad Sci USA 103: 1959-1963.

Markram H, Lubke J, Frotscher M, Roth A, Sakmann B (1997). Physiology and anatomy of synaptic connections between thick tufted pyramidal neurones in the developing rat neocortex. J Physiol 500(Pt 2): 409-440.

Markram H, Toledo-Rodriguez M, Wang Y, Gupta A, Silberberg G, $\mathrm{Wu} C$ (2004). Interneurons of the neocortical inhibitory system. Nat Rev Neurosci 5: 793-807.

Marlin JJ, Carter AG (2014). GABA-A receptor inhibition of local calcium signaling in spines and dendrites. $J$ Neurosci 34: 15898-15911.

McLean HA, Caillard O, Khazipov R, Ben-Ari Y, Gaiarsa JL (1996). Spontaneous release of GABA activates GABAB receptors and controls network activity in the neonatal rat hippocampus. J Neurophysiol 76: 1036-1046.

Nathan T, Jensen MS, Lambert JD (1990). The slow inhibitory postsynaptic potential in rat hippocampal CA1 neurones is blocked by intracellular injection of QX-314. Neurosci Lett 110: 309-313.

Oh SW, Harris JA, Ng L, Winslow B, Cain N, Mihalas S et al (2014). A mesoscale connectome of the mouse brain. Nature 508: 207-214.

Perez-Garci E, Gassmann M, Bettler B, Larkum ME (2006). The GABAB1b isoform mediates long-lasting inhibition of dendritic $\mathrm{Ca} 2+$ spikes in layer 5 somatosensory pyramidal neurons. Neuron 50: 603-616.

Petilla Interneuron Nomenclature G, Ascoli GA, Alonso-Nanclares $\mathrm{L}$, Anderson SA, Barrionuevo G, Benavides-Piccione $\mathrm{R}$ et al (2008). Petilla terminology: nomenclature of features of GABAergic interneurons of the cerebral cortex. Nat Rev Neurosci 9: $557-568$

Pfeffer CK, Xue M, He M, Huang ZJ, Scanziani M (2013). Inhibition of inhibition in visual cortex: the logic of connections between molecularly distinct interneurons. Nat Neurosci 16: 1068-1076.

Ramaswamy S, Markram H (2015). Anatomy and physiology of the thick-tufted layer 5 pyramidal neuron. Front Cell Neurosci 9: 233.

Resnick HS, Yehuda R, Pitman RK, Foy DW (1995). Effect of previous trauma on acute plasma cortisol level following rape. Am J Psychiatry 152: 1675-1677.

Sauseng P, Griesmayr B, Freunberger R, Klimesch W (2010). Control mechanisms in working memory: a possible function of EEG theta oscillations. Neurosci Biobehav Rev 34: $1015-1022$. 
Schwenk J, Metz M, Zolles G, Turecek R, Fritzius T, Bildl W et al (2010). Native GABA(B) receptors are heteromultimers with a family of auxiliary subunits. Nature 465: 231-235.

Schwenk J, Perez-Garci E, Schneider A, Kollewe A, Gauthier-Kemper A, Fritzius T et al (2016). Modular composition and dynamics of native GABAB receptors identified by highresolution proteomics. Nat Neurosci 19: 233-242.

Shepherd GM (2013). Corticostriatal connectivity and its role in disease. Nat Rev Neurosci 14: 278-291.

Sjostrom PJ, Hausser M (2006). A cooperative switch determines the sign of synaptic plasticity in distal dendrites of neocortical pyramidal neurons. Neuron 51: 227-238.

Sloviter RS, Ali-Akbarian L, Elliott RC, Bowery BJ, Bowery NG (1999). Localization of $\operatorname{GABA}(\mathrm{B})$ (R1) receptors in the rat hippocampus by immunocytochemistry and high resolution autoradiography, with specific reference to its localization in identified hippocampal interneuron subpopulations. Neuropharmacology 38: 1707-1721.

Sohal VS, Zhang F, Yizhar O, Deisseroth K (2009). Parvalbumin neurons and gamma rhythms enhance cortical circuit performance. Nature 459: 698-702.

Somogyi P, Katona L, Klausberger T, Lasztoczi B, Viney TJ (2014). Temporal redistribution of inhibition over neuronal subcellular domains underlies state-dependent rhythmic change of excitability in the hippocampus. Phil Trans R Soc Lond Ser B Biol Sci 369: 20120518

Taniguchi H, He M, Wu P, Kim S, Paik R, Sugino K et al (2011). A resource of Cre driver lines for genetic targeting of GABAergic neurons in cerebral cortex. Neuron 71: 995-1013.

Terunuma M, Vargas KJ, Wilkins ME, Ramirez OA, JaureguiberryBravo M, Pangalos MN et al (2010). Prolonged activation of NMDA receptors promotes dephosphorylation and alters postendocytic sorting of GABAB receptors. Proc Natl Acad Sci USA 107: 13918-13923.

Thomson AM, Bannister AP (1998). Postsynaptic pyramidal target selection by descending layer III pyramidal axons: dual intracellular recordings and biocytin filling in slices of rat neocortex. Neuroscience 84: 669-683.

van Wingen GA, Geuze E, Vermetten E, Fernandez G (2012). The neural consequences of combat stress: long-term follow-up. Mol Psychiatry 17: 116-118.

Williams SR, Mitchell SJ (2008). Direct measurement of somatic voltage clamp errors in central neurons. Nat Neurosci 11: 790-798. Yusufishaq S, Rosenkranz JA (2013). Post-weaning social isolation impairs observational fear conditioning. Behav Brain Res 242: 142-149. 